\title{
Idiopathic pulmonary arteriovenous malformations: clinical and imaging
} characteristics

\author{
H.H. Wong*, R.P. Chan" ${ }^{\#}$, R. Klatt ${ }^{\top}$ and M.E. Faughnan ${ }^{+, \S, f}$
}

ABSTRACT: Pulmonary arteriovenous malformations (PAVMs) can cause stroke, brain abscess or life-threatening haemorrhage. Most PAVMs are associated with hereditary haemorrhagic telangiectasia (HHT). The aim of the present study was to describe the clinical presentation and treatment outcomes of those with idiopathic PAVMs, which has not previously been described in the literature.

Patients with idiopathic PAVMs were identified at our HHT centre. Retrospective review of charts and imaging were performed.

20 patients were identified with idiopathic PAVMs. The most common symptoms reported were dyspnoea and migraines (50 and $30 \%$ of patients, respectively). Previous complications of PAVMs included haemoptysis (20\%), stroke (20\%) and brain abscess (5\%). A total of 28 focal PAVMs were identified. Most patients (80\%) had a solitary PAVM. 13 out of 28 PAVMs (46\%) were located in the lower lobes. Most were simple and fistulous rather than complex and plexiform. Transcatheter embolotherapy was performed in 17 patients and was successful in improving oxygenation in all cases.

The clinical manifestations and complications of idiopathic PAVMs are similar to those associated with HHT. Idiopathic PAVMs are anatomically similar to HHT-related PAVMs except for a greater number of solitary PAVMs and a lack of lower lobe predominance. Transcatheter embolotherapy is a safe and effective method for treating idiopathic PAVMs.

KEYWORDS: Arteriovenous malformations, embolisation, hereditary haemorrhagic telangiectasia, lung, therapeutic

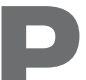
ulmonary arteriovenous malformations (PAVMs) are abnormal pulmonary blood vessels in which there is a direct connection between arterial and venous vessels without intervening capillaries. As a result of this anatomical abnormality, PAVMs can be associated with a wide spectrum of clinical manifestations. These include life-threatening haemorrhage, and symptoms and complications from paradoxical embolisation, such as stroke and brain abscess $[1,2]$.

Approximately $80-95 \%$ of PAVMs are associated with hereditary haemorrhagic telangiectasia (HHT) [3-5], also known as Osler-Weber-Rendu syndrome. A number of other conditions are more rarely associated with acquired PAVMs, such as hepatic cirrhosis [6], schistosomiasis [7], mitral stenosis [8], trauma [8], actinomycosis [8], Fanconi's syndrome [9], and metastatic thyroid carcinoma [10] and other cancers. The remainder of PAVMs are presumed to be idiopathic in nature.

PAVMs are usually described according to their anatomical characteristics. Approximately $85 \%$ of
PAVMs are simple, in which the arterial supply arises from one or more branches of a single segmental pulmonary artery [11]. Most of the remainder are complex PAVMs, which have multiple arterial feeder vessels from more than one pulmonary segment. A smaller percentage of PAVMs are diffuse, in which there is disseminated involvement of multiple pulmonary segments [12]. PAVMs can be further characterised according to their radiological appearance. The fistula-type PAVM has a feeding artery directly connected to a draining vein, with an intervening single aneurysmal sac. Less commonly, PAVMs are plexiform with a multiseptated aneurysm or a cluster of vascular channels.

Historically, symptomatic PAVMs were treated surgically. But since the advent of embolotherapy, percutaneous transcatheter embolisation with coils has significantly decreased the rate of complications arising from PAVMs [3-5, 12]. The International HHT Guidelines recommend that PAVMs be embolised preventatively, whether or

\section{AFFILIATIONS}

*Dept of Medicine, Division of Respirology,

"Dept of Molecular Genetics, Division of Clinical \& Metabolic Genetics, The Hospital for Sick Children,

+Dept of Medicine, Division of Respirology,

${ }^{\S}$ Keenan Research Center,

${ }^{f}$ Li Ka Shing Knowledge Institute, St Michael's Hospital, University of Toronto, Toronto, and

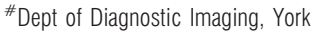
Central Hospital, Richmond Hill, Canada.

\section{CORRESPONDENCE}

M.E. Faughnan

University of Toronto, HHT Program and Pulmonary Function Laboratory, St Michael's Hospital

Division of Respiratory Medicine

30 Bond Street

Suite 6049

Toronto

ON

M5B 1W8

USA

E-mail: Faughnanm@smh.ca

Received:

May 122010

Accepted after revision:

Nov 292010

First published online:

Dec 222010

Online ISSN 1399-3003 
not they are symptomatic, in order to decrease the risk of complications [13]. The literature supports targeting PAVMs with a feeding artery diameter of $\geqslant 3 \mathrm{~mm}$ [14, 15], with consideration for embolising PAVMs with a feeding artery diameter as small as $2 \mathrm{~mm}$ [13].

Although there have been many recent large case series describing the clinical course and treatment outcomes of PAVMs [3-5, 16, 17], these case series have been almost entirely comprised of HHT patients. Patients with idiopathic PAVMs have never been described and characterised as a separate entity in the literature. The purpose of this study was to describe the clinical presentation and treatment outcomes of patients with idiopathic PAVMs.

\section{SUBJECTS AND METHODS \\ Study population}

The HHT clinic at St Michael's Hospital in Toronto (Canada) is a tertiary specialised HHT centre. After initial patient assessment, patient data from those who had given consent were entered into the Toronto HHT Database. Patients listed in the database and seen in clinic between May 1999 and August 2007 were recruited retrospectively. Approval from the St Michael's Hospital Research Ethics Board was obtained. Patients with PAVMs, confirmed by unenhanced computed tomography (CT) of the chest, were included in the study. Those with "definite" HHT according to the Curaçao criteria $[13,18]$ or with a definite family history for HHT were excluded from this study. Any patients that had other known causes of PAVMs were also excluded.

\section{Curaçao criteria for diagnosis of HHT}

HHT is a clinical diagnosis based on the presence of recurrent epistaxis, mucocutaneous telangiectasia, arteriovenous malformations (AVMs) involving visceral organs, and family history of HHT. HHT patients were identified using the International Clinical Diagnostic (Curaçao) Criteria [18], in which the diagnosis of HHT is definite when at least three out of the four of the criteria are present, suspected when two criteria are present and unlikely when only one criterion is present.

\section{Genetic testing for HHT}

All patients were offered genetic testing for HHT. Previous studies have shown that $\sim 80 \%$ of HHT families have a diseasecausing mutation in either the endoglin gene (ENG) on chromosome 9, coding for endoglin protein [19], or activin receptor-like kinase gene (ACVRL1) on chromosome 12, coding for the activin receptor-like kinase 1 protein [20]. More recently, mutations of the gene called mother against decapentaplegic homologue $4(M A D H 4)$, coding for the SMAD4 protein, have been described in $1-3 \%$ of HHT patients with a rare syndrome of combined familial juvenile polyposis (JP) and HHT [21], but can also rarely occur in HHT patients without JP [22]. Whenever possible, all three of these known gene mutations were tested.

\section{Clinical assessments and follow-up}

A detailed personal and family history was obtained from each patient on their initial visit to screen for potential clinical manifestations of PAVMs and HHT. If patients were found to have a history of epistaxis, they were referred to an experienced otolaryngologist to look for telangiectases. Each patient had routine bloodwork, an oxygen shunt study, agitated saline transthoracic contrast echocardiography (as previously described $[23,24]$ ) and chest CT performed as routine baseline assessment for suspected PAVMs. Also, all subjects underwent further imaging studies to screen for AVMs in other visceral organs commonly affected in HHT. Each patient had brain magnetic resonance imaging to rule out cerebral AVMs and mesenteric Doppler ultrasound to screen for intrahepatic shunt. All were referred to an interventional radiology dept for pulmonary angiography and possible embolotherapy. Patients who underwent embolotherapy were admitted to hospital for the procedure, observed overnight and discharged the following day. Transcatheter embolotherapy was performed from a transfemoral vein approach with the placement of embolisation coils in the distal aspect of all PAVMs with a feeding artery diameter $\geqslant 3 \mathrm{~mm}$, based on CT measurement, according to standard technique as previously described [25].

In general, following embolotherapy, patients were reassessed in the HHT clinic at intervals of 1-2 months, $1 \mathrm{yr}$ and then every 1-3 yrs. Oxygen shunt study and chest radiograph were performed at the 1-2-month follow-up visit. Chest CT was performed at the 1-yr follow-up, then every 1-3 yrs after embolotherapy, depending on the presence of small untreated PAVMs. In most cases, patients were seen every other year if their PAVMs remained stable after embolotherapy.

\section{Design and data collection}

Data regarding patient demographics, laboratory results, oxygen shunt studies and agitated saline transthoracic contrast echocardiography studies at presentation and during followup, including post-treatment studies, were obtained from our HHT Clinic Database and medical records. Data regarding genetic test results, clinical presentation and treatment outcomes were further gathered from a retrospective clinic chart review. All available chest CTs and pulmonary angiograms (including those before and after embolotherapy) were rereviewed with an experienced radiologist (R.P. Chan) to collect data regarding PAVM anatomical characteristics as well as imaging outcomes following embolisation.

\section{Data analysis}

Data are presented as percentages, or means with ranges or standard deviations as appropriate. Data are tabulated and presented in graph and chart format where appropriate.

\section{RESULTS}

\section{Patient demographic and clinical presentation}

$20(14 \%)$ out of a total of 139 patients met the study criteria, with PAVMs. The mean age at time of presentation to our clinic was 47 (range 25-86) yrs with 13 (65\%) out of 20 patients being female. Nine $(45 \%)$ of 20 patients were diagnosed with PAVMs as a result of symptoms or complications related to their PAVMs. Of these, five (25\%) patients presented with serious complications related to their PAVM, such as cerebral vascular accident (CVA), brain abscess or haemoptysis. PAVMs were found incidentally in the remaining $11(55 \%)$ patients. Symptoms related to PAVMs found on initial assessment included dyspnoea, haemoptysis and migraine. 


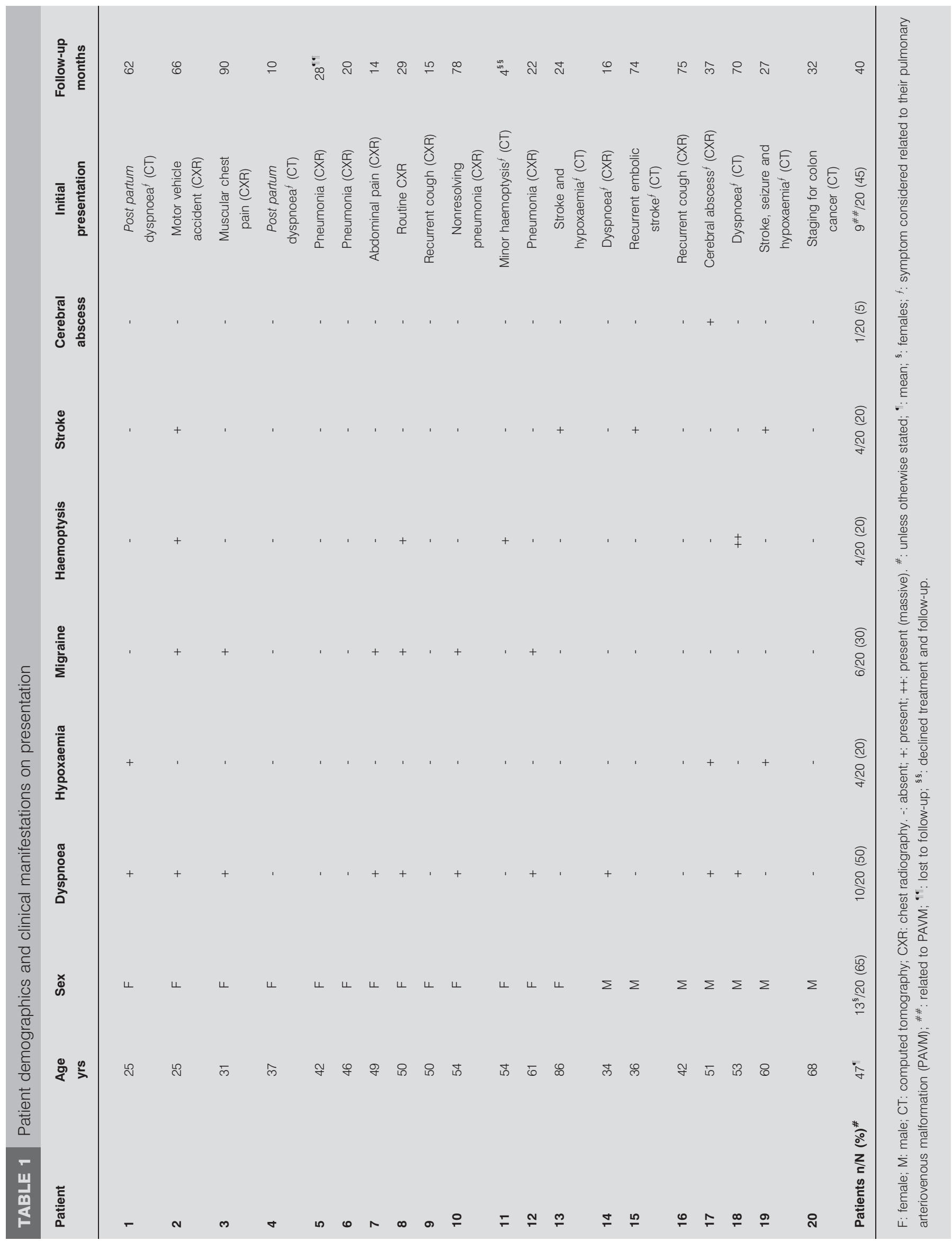


Patient demographics along with patients' initial presentation are summarised in table 1 .

Although all patients with "definite" HHT according to the Curaçao criteria were excluded, seven (35\%) out of the remaining 20 patients had one other clinical feature in their history compatible with possible HHT (patients 2, 10, 13 and 16-19). This group of patients has a mean \pm SD age of $53 \pm 18$ (range 25-85) yrs. Patients 2 and 13 had a history of epistaxis, the former with a normal otolaryngology exam and the latter not assessed by otolaryngology. Physical findings of mucocutaneous telangiectasias were noted in patients 10, 18 and 19. Finally, evidence of hepatic shunt was noted on imaging studies in patients 16 and 17.

\section{Genetic testing}

$16(80 \%)$ out of 20 patients had genetic testing results that were negative for the two most common genes predisposing patients to HHT, ENG and ACVRL1. Of these patients, all except for patients 8, 17 and 18 also underwent testing for MADH4 mutation, and were negative. Patients 5 and 10 are no longer being followed by our clinic and patient 11 declined genetic testing. Finally, one patient (patient 14) tested positive for an HHT-causative ENG gene mutation (fig. 1).

\section{Imaging characteristics}

A total of 28 focal idiopathic PAVMs were identified in 19 out of 20 patients. Imaging characteristics are not reported in detail for one patient as they had bilateral diffuse PAVMs. $16(80 \%)$ patients had a single PAVM, two $(10 \%)$ patients had two PAVMs and one (5\%) patient had eight PAVMs. Of the 28 focal idiopathic PAVMs, 13 (46\%) were located in the lower lobes (fig. 2). $26(93 \%)$ out of 28 PAVMs were simple while the remainder were complex. $23(82 \%)$ out of 28 PAVMs were fistulas while the remainder were plexiform PAVMs. The mean feeding artery diameter was 4 (range 1-13) $\mathrm{mm}$. The imaging characteristics of all 20 patients are presented in table 2 .

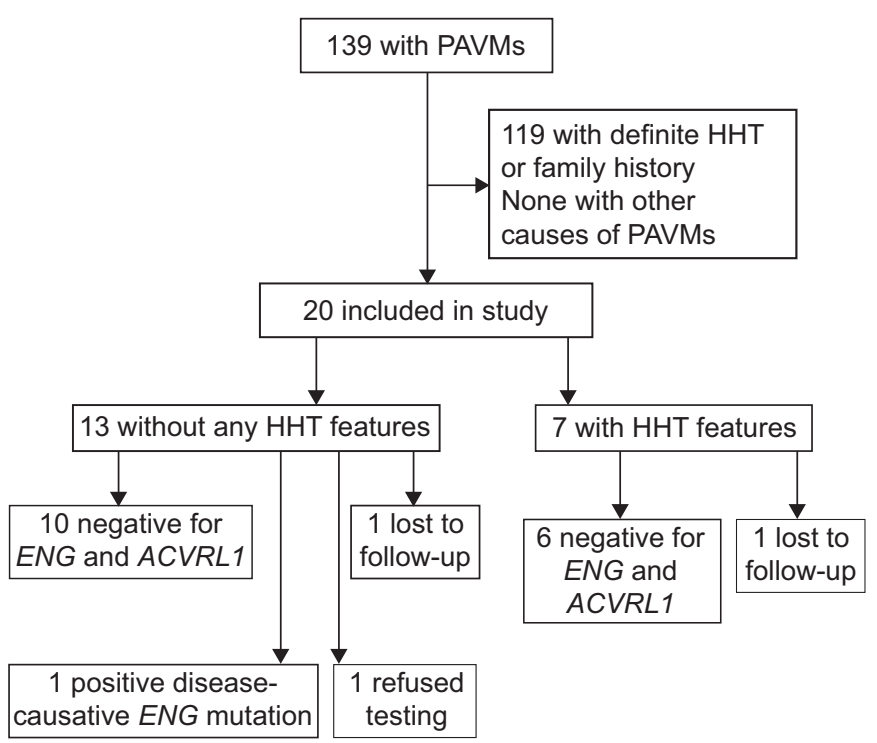

FIGURE 1. Distribution of idiopathic pulmonary arteriovenous malformation (PAVM) cases and genotypes. HHT: hereditary haemorrhagic telangiectasia.

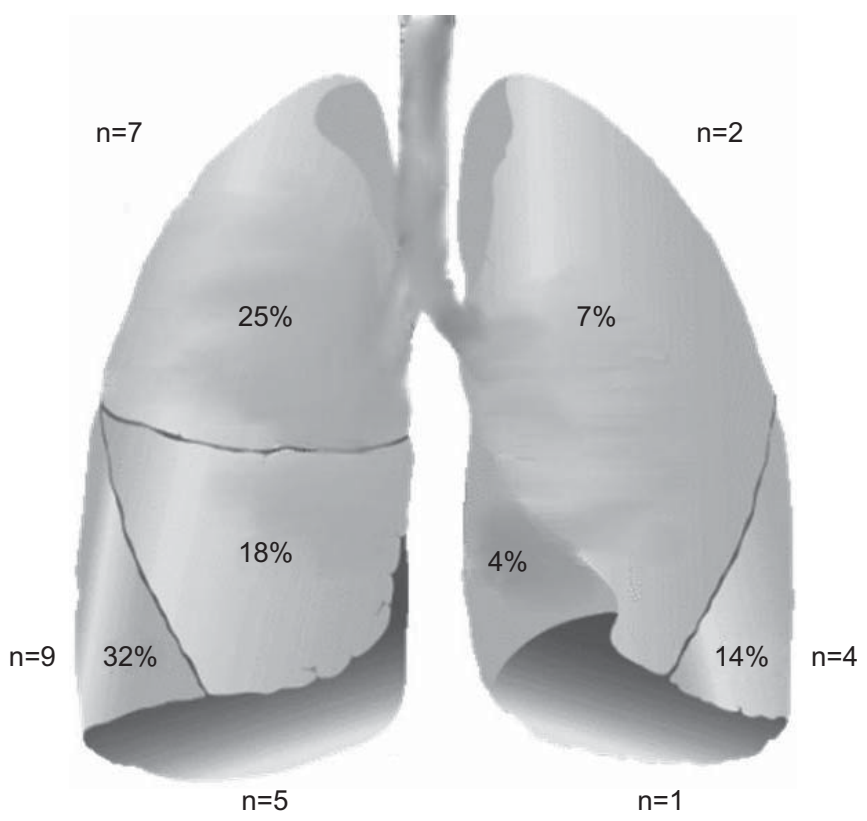

FIGURE 2. Location of idiopathic pulmonary arteriovenous malformations.

\section{Treatment outcomes}

Embolisation was performed for 20 (71\%) out of 28 PAVMs in a total of 23 sessions (including reperfusion treatments) for 17 out of 20 patients (table 2). Reperfusion was assessed 1 yr after embolisation and occurred in five out of 17 patients, each of whom required subsequent embolisation sessions. There was immediate occlusion of flow in the feeding artery of all 20 treated PAVMs after all 23 sessions of transcatheter embolotherapy. Of the 13 patients in whom both pre- and postembolisation arterial blood gas data were available, all had improvement in shunt, with 10 having complete normalisation of the estimated shunt fraction (normal $<8 \%$, based on local receiver operating characteristic curve). The mean calculated shunt fraction decreased from $12.4 \%$ (range $7.0-26.4 \%$ ) to $6.0 \%$ (range 2.0-10.0\%). No major procedural complications, such as paradoxical embolism or haemoptysis, occurred as a result of embolisation.

\section{Follow-up}

Patients were followed for a mean of 40 (range 4-90) months, as shown in table 1. Of all 20 patients, one declined follow-up and another was lost to follow-up. There were no deaths. No patients suffered from serious complications related to PAVMs, such as CVA, brain abscess or haemoptysis, after embolotherapy.

\section{DISCUSSION}

PAVMs are known to cause serious complications, such as stroke, cerebral abscess and life-threatening haemorrhage $[3-5,16,17]$. However, all previous studies were largely comprised of HHT patients. To our knowledge, this study is the first to show that idiopathic PAVMs appear to behave similarly to HHT-related PAVMs by presenting with similar symptoms and complications at comparable frequencies (table 3). However, there are a few notable differences between the two groups. 


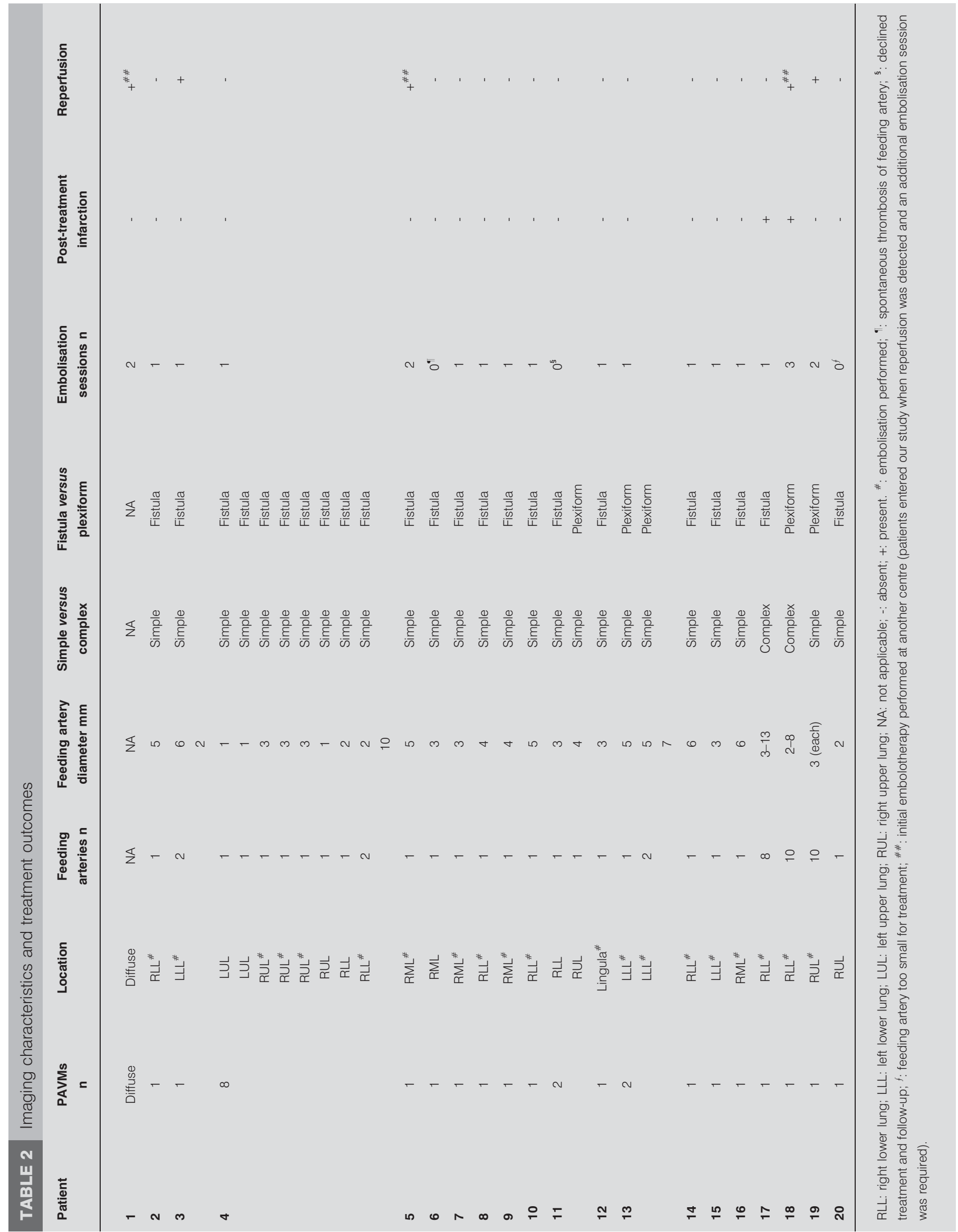


TABLE 3 Comparison of clinical manifestations in our series to other pulmonary arteriovenous malformation series

\begin{tabular}{|c|c|c|c|c|c|c|}
\hline & \multirow[t]{2}{*}{ Present study } & \multicolumn{5}{|c|}{ First author [ref.] } \\
\hline & & SWANSON [16] & GUPTA [3] & MAGER [4] & POLLAK [5] & Cottin [17] \\
\hline Patients n & 20 & 93 & 66 & 112 & 155 & 126 \\
\hline $\begin{array}{l}\text { Age yrs mean } \pm \text { SD } \\
\text { (range) }\end{array}$ & $48 \pm 15$ (25-86) & 40 (5-83) & $44(13-77)$ & 45 (7-85) & $45(7-77)$ & $43 \pm 17(10-79)$ \\
\hline Hepatic shunt & 10 & & & 4 & & 10 \\
\hline HНT \% & 0 & 56 & 83 & 96 & 95 & 100 \\
\hline Dyspnoea \% & 50 & 53 & 56 & & 59 & 56 \\
\hline Cyanosis \% & 0 & 29 & 29 & & & 18 \\
\hline Polycythaemia \% & 5 & 13 & 27 & & & \\
\hline Migraine \% & 30 & & 38 & & 46 & 16 \\
\hline Brain abscess & 5 & 5 & 17 & 7 & 9 & 19 \\
\hline Other abscess & 0 & & 3 & 1 & 6 & 4 \\
\hline Asymptomatic & 30 & 16 & & 34 & 16 & 15 \\
\hline
\end{tabular}

HHT: hereditary haemorrhagic telangiectasia; CVA: cerebral vascular accident.

We observed that idiopathic PAVMs are similar to PAVMs associated with HHT in that the majority are simple (93\%) and fistulous $(82 \%)$ in morphology, rather than complex and plexiform (table 2). However, patients with idiopathic PAVMs differ notably from those in the HHT series in that the majority ( $80 \%$ in this study) present with solitary PAVMs, compared with $<40 \%$ in HHT patients $[3,16,21]$. Also, idiopathic PAVMs appear to be more evenly distributed in all areas of the lung, differing from the 60-95\% lower lobe preponderance in HHT patients suggested by numerous other studies [3-4, 14, 17].

A few possible inferences can be made from these two differences. First, patients with idiopathic PAVMs might have a lower incidence of platypnoea and orthodeoxia that usually results from increased ventilation-perfusion mismatching in an upright position, an observation usually seen in lower lobe preponderance. Secondly, MAGER et al. [4] showed in their study that patients with solitary PAVMs were more likely to have a favourable outcome after embolotherapy than those with multiple PAVMs. This suggests a possible better treatment outcome for patients with idiopathic PAVMs who undergo embolotherapy. Lastly, because idiopathic PAVMs are more likely to be solitary and therefore less likely to be associated with large right-to-left shunt, this might in part explain why patients with idiopathic PAVMs might have a lower frequency of cyanosis and polycythaemia (table 3). Also, previous HHT series have shown an association between number of PAVMs and cerebral abscess risk [26]. This might explain why idiopathic PAVMs are associated with a lower frequency of cerebral abscess in our series when compared with others.

Our study suggests that transcatheter embolotherapy is a safe and effective method of treating idiopathic PAVMs, as shown in table 2. There were no major complications from the procedure, such as paradoxical embolism or haemoptysis, and no long-term symptoms or sequelae. During an average 3-yr follow-up period after embolisation, all patients reported improved dyspnoea and none developed serious PAVMrelated complications.

The prevalence of HHT in patients with PAVMs has historically ranged between 50 and $80 \%$ [16, 27-30], though more recent studies suggest that it may be closer to $80-95 \%$ [3-5]. This study also suggests a HHT prevalence of $86 \%$ among all patients with PAVMs in our clinic database. The trend towards higher prevalence of HHT as the underlying diagnosis is probably the result of improving recognition of the diagnosis of HHT, and association between HHT and PAVMs. Furthermore, we now have better diagnostic tools, including imaging and genetic testing. However, since most of the centres reporting PAVM series are HHT tertiary referral centres, one should be cautious in interpreting these numbers, since referral bias might factitiously increase the prevalence of HHT among patients with PAVMs.

The most significant limitation of our study is the small number of patients, but as this is the first series of wellcharacterised patients with idiopathic PAVMs, we believe it contributes significantly to the literature. We do not have complete genetic data in all patients, but believe the available results are informative. Currently, HHT is still a clinical diagnosis and existing genetic testing is only $\sim 80 \%$ sensitive [31]. This is because introns (noncoding regions) and promoter regions of ENG, ACVRL1 and MADH4 are not typically sequenced, given the low yield of mutations in these regions. Furthermore, there appears to be at least two other chromosomes linked to HHT, though the specific gene loci have not 
been identified [32-34]. Therefore, it is possible that some of our idiopathic PAVM patients might in fact have HHT, but with a mild clinical phenotype and an unrecognised causative mutation.

It remains possible that some of the patients in our series have unrecognised HHT, with this being especially plausible for the seven patients who had epistaxis, mucocutaneous telangiectases or hepatic shunt. HHT is often unrecognised in children and young adults, as the clinical expression of HHT is agerelated [35]. For example, $<50 \%$ of children with HHT have epistaxis or telangiectasia [36] but $\sim 90 \%$ of adults $>50 \mathrm{yrs}$ of age have recurrent epistaxis [35, 37]. However, given that the mean age in our group of "possible" patients is $>50 \mathrm{yrs}$, none had a family history of HHT and all (six out of six) had negative genetic testing for ENG and ACVRL1 mutation, it is unlikely that many of these patients have HHT. Interestingly, one patient with epistaxis (and normal nasal mucosa on examination by an otolaryngologist) was originally included in our study but was lost to follow-up. They were later excluded from our study when they re-presented to the clinic 6 yrs later with new telangiectases (and, thus, definite diagnosis of HHT). This reinforces the need for long-term follow-up of patients with idiopathic PAVMs for the presence of HHT. Though patient 14 was found to carry an ENG mutation, this patient cannot be confirmed to have HHT, given the absence of clinical features and family history. It would not be surprising to find that ENG mutation could predispose to various vascular malformations in conditions other than HHT, though this has not been explored in the literature to date.

In conclusion, the clinical manifestations and complications of idiopathic PAVMs are very similar to those associated with HHT. Idiopathic PAVMs are anatomically similar to HHTrelated PAVMs, with the notable differences of a greater proportion of solitary PAVMs and a lack of lower lobe predominance. Finally, transcatheter embolotherapy is a safe and effective method for treating patients with idiopathic PAVMs.

\section{SUPPORT STATEMENT}

The study was supported by grants from the Li Ka Shing Knowledge Institute of St Michael's Hospital and Nelson Arthur Hyland Foundation (to M.E. Faughnan).

\section{STATEMENT OF INTEREST}

None declared.

\section{ACKNOWLEDGEMENTS}

We would like to acknowledge and thank E. Granatstein (St Michael's Hospital, Toronto, ON, Canada) for all her help with maintaining the Toronto HHT Database.

\section{REFERENCES}

1 Faughnan ME, Granton JT, Young LH. The pulmonary vascular complications of hereditary haemorrhagic telangiectasia. Eur Respir J 2009; 33: 1186-1194.

2 Post MC, van Gent MW, Plokker HW, et al. Pulmonary arteriovenous malformations associated with migraine with aura. Eur Respir J 2009; 84: 882-887.

3 Gupta P, Mordin C, Curtis J, et al. Pulmonary arteriovenous malformations: effect of embolization on right-to-left shunt, hypoxemia, and exercise tolerance in 66 patients. Am J Roentgenol 2002; 179: 347-355.

4 Mager JJ, Overtoom TT, Blauw $\mathrm{H}$, et al. Embolotherapy of pulmonary arteriovenous malformations: long-term results in 112 patients. J Vasc Interv Radiol 2004; 15; 451-456.

5 Pollak JS, Saluja S, Thabet A, et al. Clinical and anatomic outcomes after embolotherapy of pulmonary arteriovenous malformations. J Vasc Interv Radiol 2006; Jan, 17: 35-44.

6 Lange PA, Stoller JK. The hepatopulmonary syndrome. Ann Intern Med 1995; 122: 521-529.

7 de Faria JL, Czapski K, Ribierto, et al. Cyanosis in Manson's schistosomiasis: role of pulmonary schistosomatic arteriovenous fistulas. Am Heart J 1957; 54: 196-204.

8 Prager RL, Laws KH, Bender Jr HW. Arteriovenous fistula of the lung. Ann Thorac Surg 1983; 36: 231-239.

9 Taxman RM, Halloran MJ, Parker BM. Multiple pulmonary arteriovenous malformations in association with Fanconi's syndrome. Chest 1973; 64: 118-120.

10 Pierce JA, Reagan WP, Kimball RW. Unusual cases of pulmonary arteriovenous fistulas with a note on thyroid carcinoma as a cause. New Engl J Med 1959; 18: 901-907.

11 White RI Jr, Pollak JS, Wirth JA. Pulmonary arteriovenous malformations: diagnosis and transcatheter embolotherapy. J Vasc Interv Radiol 1996; 7: 787-804.

12 Faughnan ME, Lui YW, Wirth JA, et al. Diffuse pulmonary arteriovenous malformations: characteristics and prognosis. Chest 2000; 117: 31-38.

13 Faughnan ME, Palda VA, Garcia-Tsao G, et al. International guidelines for the diagnosis and management of hereditary hemorrhagic telangiectasia. J Med Genet 2011; 48: 73-87.

14 White RI Jr, Lynch-Nyhan A, Terry P, et al. Pulmonary arteriovenous malformations: techniques and long-term outcome of embolotherapy. Radiology 1988; 169: 663-669.

15 Rosenblatt M, Pollak JS, Fayad PB, et al. Pulmonary arteriovenous malformations: what size should be treated to prevent embolic stroke? Radiology 1992; 185: P134.

16 Swanson KL, Prakash UB, Stanson AW. Pulmonary arteriovenous fistulas: Mayo Clinic experience, 1982-1997. Mayo Clin Proc 1999; 74: 671-680.

17 Cottin V, Chinet $\mathrm{T}$, Lavolé A, et al. Pulmonary arteriovenous malformations in hereditary hemorrhagic telangiectasia. Medicine 2007; 86: 1-17.

18 Shovlin CL, Guttmacher AE, Buscarini E, et al. Diagnostic criteria for hereditary hemorrhagic telangiectasia (Rendu-Osler-Weber syndrome). Am J Med Genet 2000; 91: 66-67.

19 McAllister KA, Grogg KM, Johnson DW, et al. Endoglin, a TGF- $\beta$ binding protein of endothelial cells, is the gene for hereditary haemorrhagic telangiectasia type 1. Nat Genet 1994; 8: 345-351.

20 Berg JN, Gallione CJ, Stenzel TT, et al. The activin receptor-like kinase 1 gene: genomic structure and mutations in hereditary hemorrhagic telangiectasia type 2. Am J Hum Genet 1997; 61: 60-67.

21 Gallione CJ, Repetto GM, Legius E, et al. A combined syndrome of juvenile polyposis and hereditary haemorrhagic telangiectasia associated with mutations in MADH4 (SMAD4). Lancet 2004; 363: 852-859.

22 Gallione CJ, Richards JA, Letteboer TG, et al. SMAD4 mutations found in unselected HHT patients. J Med Genet 2006; 43: 793-797.

23 van Gent MW, Post MC, Luermans JG, et al. Screening for pulmonary arteriovenous malformations using transthoracic contrast echocardiography: a prospective study. Eur Respir J 2009; 33: 85-91.

24 Parra JA, Bueno J, Zarauza J, et al. Graded contrast echocardiography in pulmonary arteriovenous malformations. Eur Respir J 2010; 35: 1279-1285.

25 Prasad V, Chan RP, Faughnan ME. Embolotherapy of pulmonary arteriovenous malformations: efficacy of platinum versus stainless steel coils. J Vasc Interv Radiol 2004; 15: 153-160. 
26 Moussouttas M, Fayad P, Rosenblatt M, et al. Pulmonary arteriovenous malformations: cerebral ischemia and neurologic manifestations. Neurology 2000; 55: 959-964.

27 Dines DE, Seward JB, Bernatz PE. Pulmonary arteriovenous fistula. Mayo Clin Proc 1983; 58: 176-181.

28 Puskas JD, Allen MS, Moncure AC, et al. Pulmonary arteriovenous malformations: therapeutic options. Ann Thorac Surg 1993; 56 253-258.

29 Jackson JE, Whyte MKB, Allison DJ, et al. Coil embolization of pulmonary arteriovenous malformations. Cor Vasa 1990; 32: 191-196.

30 Gossage JR, Kanj G. Pulmonary arteriovenous malformations: a state of the art review. Am J Respir Crit Care Med 1998; 158: 643-661.

31 Prigoda NL, Savas S, Abdalla SA, et al. Hereditary haemorrhagic telangiectasia: mutation detection, test sensitivity and novel mutations. J Med Genet 2006; 43: 722-728.
32 Wallace GM, Shovlin CL. A hereditary haemorrhagic telangiectasia family with pulmonary involvement is unlinked to the known HHT genes, endoglin and ALK-1. Thorax 2000; 55: 685-690.

33 Bayrak-Toydemir P, McDonald J, Akarsu N, et al. A fourth locus for hereditary hemorrhagic telangiectasia maps to chromosome 7 . Am J Med Genet A 2006; 140: 2155-2162.

34 Cole SG, Begbie ME, Wallace GM, et al. A new locus for hereditary haemorrhagic telangiectasia (HHT3) maps to chromosome 5. J Med Genet 2005; 42: 577-582.

35 Porteous ME, Burn J, Proctor SJ. Hereditary haemorrhagic telangiectasia: a clinical analysis. J Med Genet 1992; 29: 527-530.

36 Al-Saleh S, Mei-Zahav M, Faughnan ME, et al. Screening for pulmonary and cerebral arteriovenous malformations in children with hereditary haemorrhagic telangiectasia. Eur Respir J 2009; 34: 875-881.

37 Plauchu H, de Chadarevian JP, Bideau A, et al. Age-related clinical profile of hereditary hemorrhagic telangiectasia in an epidemiologically recruited population. Am J Med Genet 1989; 32: 291-297. 